\title{
Impacts of Climate Variability on Salt Production in Ghana: Case of Songor Salt Project
}

\author{
A. Apambilla Roland ${ }^{1}$, H. Owusu Erasmus ${ }^{1} \&$ A. Kyerematen Rosina ${ }^{2}$ \\ ${ }^{1}$ Centre for Climate Change and Sustainability Studies, University of Ghana, Ghana \\ ${ }^{2}$ Department of Animal Biology and Conservation Science, University of Ghana, Ghana \\ Correspondence: Erasmus H. Owusu and Roland A. Apambilla, Centre for Climate Change and Sustainability \\ Studies, University of Ghana, Ghana. Tel: 233-2-4465-6359; 233-2-4868-6404. E-mail: ehowusu@ug.edu.gh; \\ raapambilla001@st.ug.edu.gh; rkyerematen@ug.edu.gh
}

Received: October 5, 2018

Accepted: December 17, 2018

Online Published: January 31, 2019

doi:10.5539/jsd.v12n1p1

URL: https://doi.org/10.5539/jsd.v12n1p1

\begin{abstract}
Climate change has been widely recognized as a multi-scalar economic and environmental problem that affects various sectors in the world today. The Songor salt project located in Ada East District of the Greater Accra region produces salt that feeds both the local and international markets with high-quality salt for consumption and industrial purposes. The industry is currently under threat due to several factors including climate change. This study was undertaken to ascertain the linkages and impacts of climate variability (temperature and rainfall) on the quantity of salt produced over the years.

Salt yield levels were correlated with temperature and rainfall data between 1980-2010 for climate data and 1996-2014 for the salt production. In exploring the impacts of climate change on the salt production, a linear multiple regression model was employed in which salt production was regressed as dependable variable against temperature and rainfall as independent variables.

The findings suggested that climate change and the quantity of salt produced are linked. Although the model results do not show statistical significant relationship, the results indicate that an increase in $1 \mathrm{~mm}$ of rainfall will lead to an increase in $0.142 \mathrm{Mt}$ of salt produced per year and vice versa whereas an increase in $1^{\circ} \mathrm{C}$ will rather lead to a decrease in $-0.488 \mathrm{Mt}$ of salt produced per year and vice versa $\left(R^{2}=0.514\right.$; Coefficient of Determination $=51.4 \%$; $P>0.05$ ). We recommend that for medium to long-term sustainability of the salt industry, adoption and mainstreaming of the salt sector into the climate change adaptation strategy as part of the overall national adaptation policy is imperative. Also, investment in efficient technologies, infrastructure and storage facilities to produce and store the salt commodity to avoid production losses and leakages are also essential to buffer the impacts of climate change.
\end{abstract}

Keywords: climate variability, temperature, rainfall, salt, wetland

\section{Introduction}

\subsection{Background}

It has been widely recognized that climate change is one of the greatest threats that currently confronts the world particularly developing countries in recent times (IPCC, 2013; Ahenkan et al., 2012). The fact that many people in developing countries depend on climate-sensitive sectors such as water resources, agriculture, and forestry resources for their livelihoods and economic transformation exacerbates this great challenge and its widespread implications become increasingly enormous. The salt production in the Songor lagoon in Greater Accra region of Ghana as an ecosystem service forms a major source of the livelihoods of the communities in and around the area. The major economic activity that the communities depend on is the salt production through both the small and commercial scales the latter been operated by the government of Ghana where many of these people are recruited as employees in various sections of the production chain. Recognizing the value of the salt industry to rural livelihoods and national development, it becomes imperative that impacts of climate change are assessed to established effects on emerging trend on the trend of the production of the commodity. This will help policy and decision makers to make informed decisions on the future sustainability of the salt industry and to assess its capacity to provide essential services especially for the local communities and also to help realize the 


\section{Sustainable Development Goals.}

\subsection{Climate Change and the Salt Industry Nexus}

The salt industry like any other sector such as rain-fed agriculture, water, ecosystems, and biodiversity is widely recognized for its sensitivity to climate variability and change (MEA, 2005, Ahenkan et al., 2012). Saline salt production is dependent on climatic variables such as wind velocity, rainfall variability, temperature variability, and solar radiation. The extent of seasonal variation of these variables may have influenced the quantity and quality of salt production at a given time. In order to establish this relationship to ascertain the trends of climate variability over the years at the Songor lagoon with a temperature and rainfall data sets from the Ghana Meteorological Agency for a 30 year period (1980-2010). This was done by exploring the impacts of these climatic variables (temperature and rainfall) on the yield $\mathrm{s}$ of salt production using a multiple linear regression model and the implications of these impacts on the livelihoods and communities that depend on the resources.

\subsection{The Songor Salt Project}

The Songor salt project is among the three main salt production centers in Ghana that feed both the local and international markets with an overall production capacity/potential of about $60,000 \mathrm{Mt} / \mathrm{a}$ from the total Songor area potential of 1,438,880 Mt/a (UGSS, 2012). The project started large-scale production in 1994. The Songor salt project currently supports about 1,000 unskilled personnel who work at the site daily in producing salt for the company. The project currently employs about 40 permanent staff at the Songor salt project which includes accountants, human resource managers, directors, engineers, drivers, security, and production and packaging staff (Songor Salt Project, 2016). This makes the salt industry at Songor, a major economic force and a key livelihood source for the surrounding communities. It also makes a major contribution to the country's Gross Domestic Product.

Salt production is facilitated through evaporation influenced by wind velocity, temperature and rainfall variability over the production area. Between 1997, 2001 and 2002, the project exceeded its production capacity and showed glimpses of a viable venture whose future was assured. Unfortunately, however, this glimmer of hope has dwindled progressively as production levels have continued to decline due to a combination of factors. Prominent among these factors is the lingering question of how much influence could variability in temperature and precipitation have in this. It is against the background of this question and the desire to delve deeper for answers that the production data for the Songor salt project was collected over a ten year period to ascertain the possible impact of climate variability and change level of production within the timeframe. This study was also informed by the fact that information on the extent and linkages of climate change on the production of this very important commodity has been lacking and has made it difficult for the sustainability of the salt industry, generally in Ghana, to be ascertained. This study was therefore aimed at exploring the possible influence of climate change on the salt industry in Ghana by addressing perceived knowledge gaps to inform policy processes as well as the development of long-term strategies and approaches in the face of climate change and climate variability.

\section{Materials and Methods}

\subsection{Study Area}

This study was conducted at the Songor lagoon and the communities that live around it. The Songor lagoon is located in the Ada East District of the Greater Accra Region of Ghana. The Songor lagoon is a coastal wetland designated as lagoon, that is a wetland of international ecological importance with an area of about 51,133.33 hectares at an elevation of $69 \mathrm{~m}$ above sea level at coordinates $5050 \% 0 \mathrm{~N}$ and $00^{\circ} 30^{\circ} 0^{\prime \prime}$ E. Among the communities around the lagoon are Koluedor, Toflokpo, and Songorya, which largely depend on the lagoon for its fishery and salt resources as their main sources of income and livelihoods. 


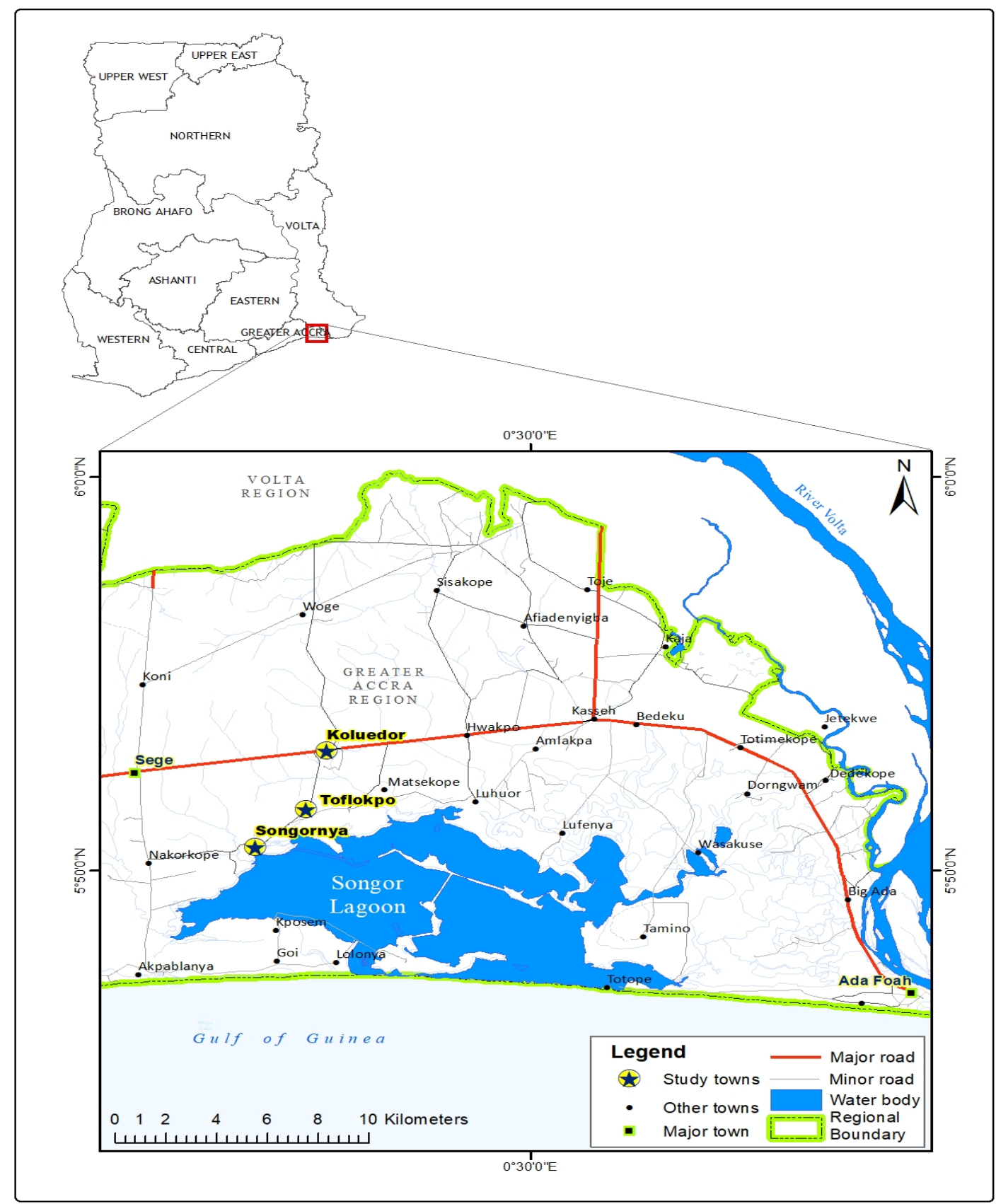

Figure 1. Map of the Songor Lagoon with the study communities

Source. Centre for Remote Sensing and Geographic Information systems (CERSGIS), Legon.

\subsection{Socio-economic Characteristics of the Study Communities}

The Ada East District has a population of about 71,671 out of which $47.5 \%$ are males and $52.5 \%$ are females. Out of this number, the higher proportions of about $70 \%$ of them are living in rural communities. (Ghana Statistical Service, 2010). The main economic activities of the people in the area include farming, intensive salt extraction, fishing and trading as their main sources of livelihoods. These areas of economic sectors dependence and livelihoods particularly the agricultural, fishing and salt mining are all noted to be climate sensitive sectors. Climate variability, therefore, presents a major threat to the sustainability of these sectors and the overall implication on the livelihoods of the communities that rely on these resources. The country also benefits economically from neighboring countries like Togo, Benin, Niger, and Burkina Faso who patronize in the salt 
produce for exportation into their local markets through the collection of foreign exchange and taxes as revenue for the communities and the District Assembly of the study area.

\subsection{Study Design and Sampling}

A purely quantitative study design was used where measurable data sets of both salt production yields were regressed against climate variability main indicators such as temperature and rainfall. This was done in order to ascertain the synergies between these variables and to establish the extent to which climate change will affect the production of salt using the Songor Salt project as a case study.

\subsection{Data Collection and Analysis}

Secondary data on climate variability) on temperature and rainfall patterns and change for a period of 30 years from 1980-2010 was collected from the Ghana Meteorological Agency. These data were used to ascertain the trend and changes in rainfall and temperature variability in the study area over the specified period. This was further useful in exploring the implications on ecosystem services changes, stability or decline as a consequence.

To be able to ascertain this link thus the interaction between the ecosystem services particularly salt production which is largely the main commodity obtained from the Songor lagoon and the climate conditions, data on the production of key ecosystem services the salt production, was collected from the Songor Salt Project (SSP) a government of Ghana Liability initiative for the production of salt to feed both the local and the international markets. The production data was from the period between 1996 and 2014 for which a linear multiple regression analysis was used to explore the impacts of climatic variables such as rainfall and temperature on the salt production at the study area. The salt production was the dependent variable against the temperature and rainfall variability as independent variables. This model was run by using SPSS version 22 software. This model equation is as follows:

$$
\mathrm{Y}=\mathrm{a}_{\mathrm{o}}+\beta_{1} \mathrm{X}_{1}+\beta_{2} \mathrm{X}_{2}+\mu_{\mathrm{o}}
$$

Where;

$\mathrm{Y}=$ Salt Production, $\mathrm{X}_{1}=$ Variation in Temperature $\mathrm{X}_{2}=$ Variation in Rainfall, $\beta=$ coefficient of regression, $\mathrm{a}_{\mathrm{o}}=$ constant and $\mu_{\mathrm{o}}=$ error margin

\section{Results}

\subsection{Evidence of Climate Variability in the Study Area}

\subsubsection{Annual Temperature Variability}

For the annual temperature variations, the proxy data by the GMET agency on temperature for the study area from the 1980 to 2010 show an increasing trend of temperature over the years. Thus, an average temperature of about $27.8^{\circ} \mathrm{C}$ was recorded in 1980 and in 2010 an average temperature of about $28.8^{\circ} \mathrm{C}$ was recorded indicating a marginal increasing trend. Thus data have shown a consistent increase in temperature observed over the years although it falls at some years. 


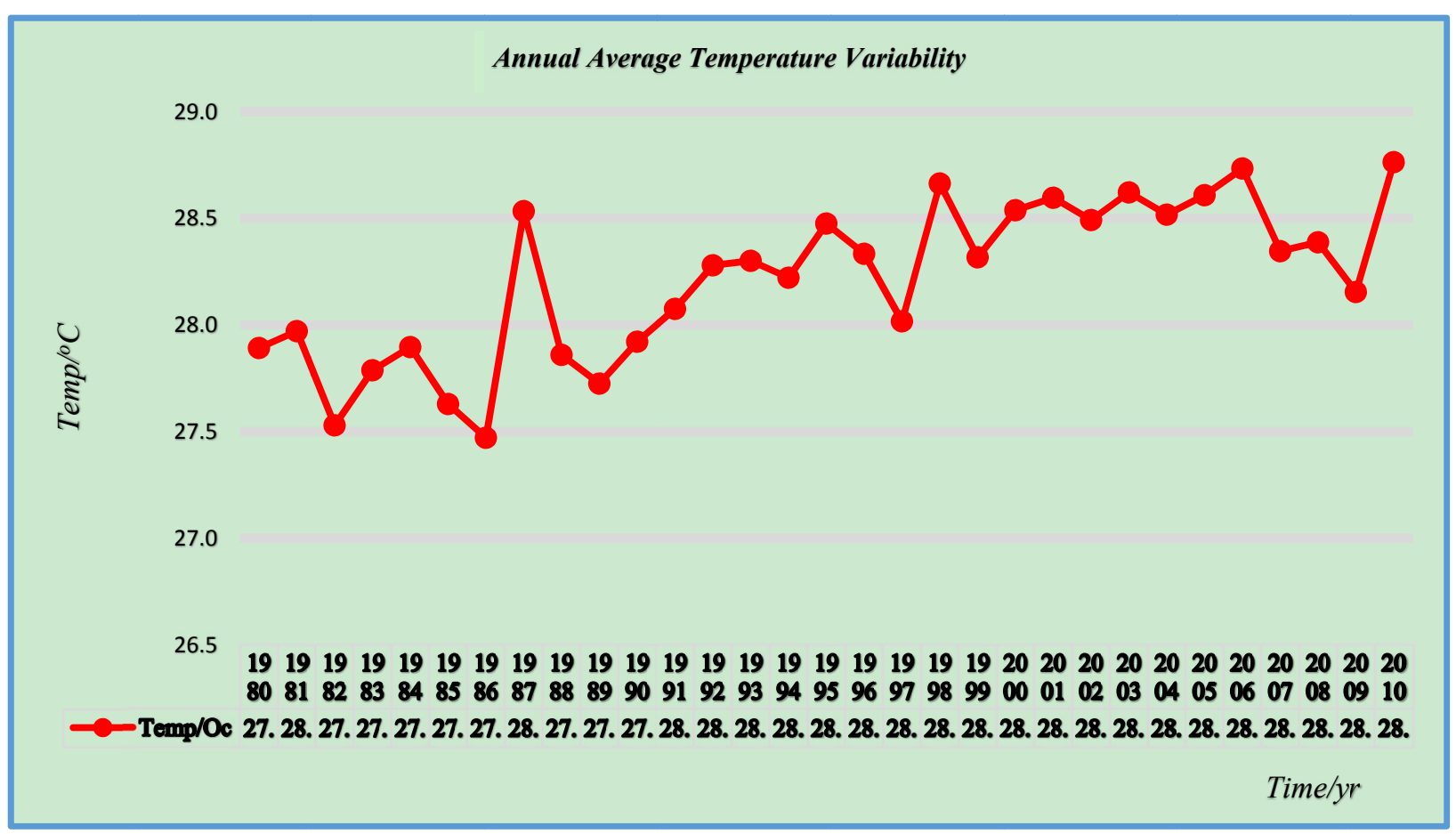

Figure 2. Annual average temperature variability of the study area

Source: Ghana Meteorological Agency

\subsubsection{Annual Rainfall Variability}

The data on rainfall variability over the study area from 1980 to 2010 from the GMET show a decreasing trend unlike the temperature with rather an increasing trend over the same period of time of monitoring. This is clearly indicated by the records from the three decades ago where rainfall was recorded as high as $104 \mathrm{~mm}$ in 1982 , $108 \mathrm{~mm}$ in 1991 and has since then declined to $89.2 \mathrm{~mm}$ and $79.8 \mathrm{~mm}$ in 2009 and 2010 respectively. Although the rainfall data in most cases appears to be erratic from year to year, the results presented here clearly indicated that annual rainfall patterns over the years continue to decrease in most parts of the years within the past three decades of the study area. 


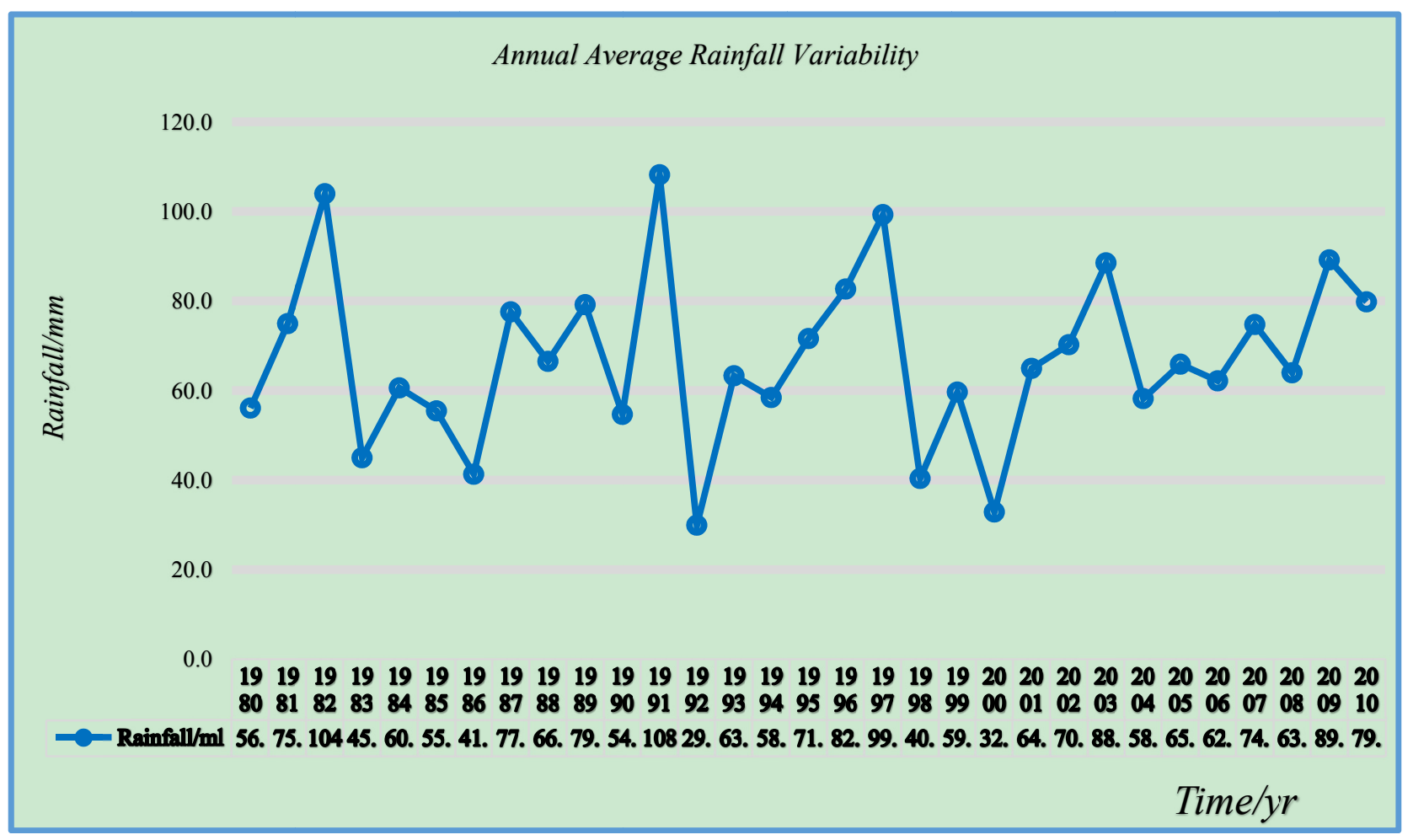

Figure 3. Annual average rainfall variability of the study area

Source: Ghana Meteorological Agency

\subsection{The Trends of Salt Production at the Songor Lagoon over the Years}

Overall, the findings indicated a declining trend over the years since production commenced in commercial quantities in 1996 to date. The highest production recorded was in 1997 followed by a drastic decline in 1998, 1999. The data indicated that the highest production levels ever recorded were in 1997 and 2001 recording 60773.03 and $61,835.25$ metric tons respectively which is above its current production capacity. The lowest levels of production since the project inception were also in 2000 and 2008 recording 10,219.25 and 9,527.75 metric tons respectively. Since 1997, 2001 and 2002 where the project has been able to reach its production capacity, it has since then not been able to attain its production capacity level but rather continues to be erratic. 


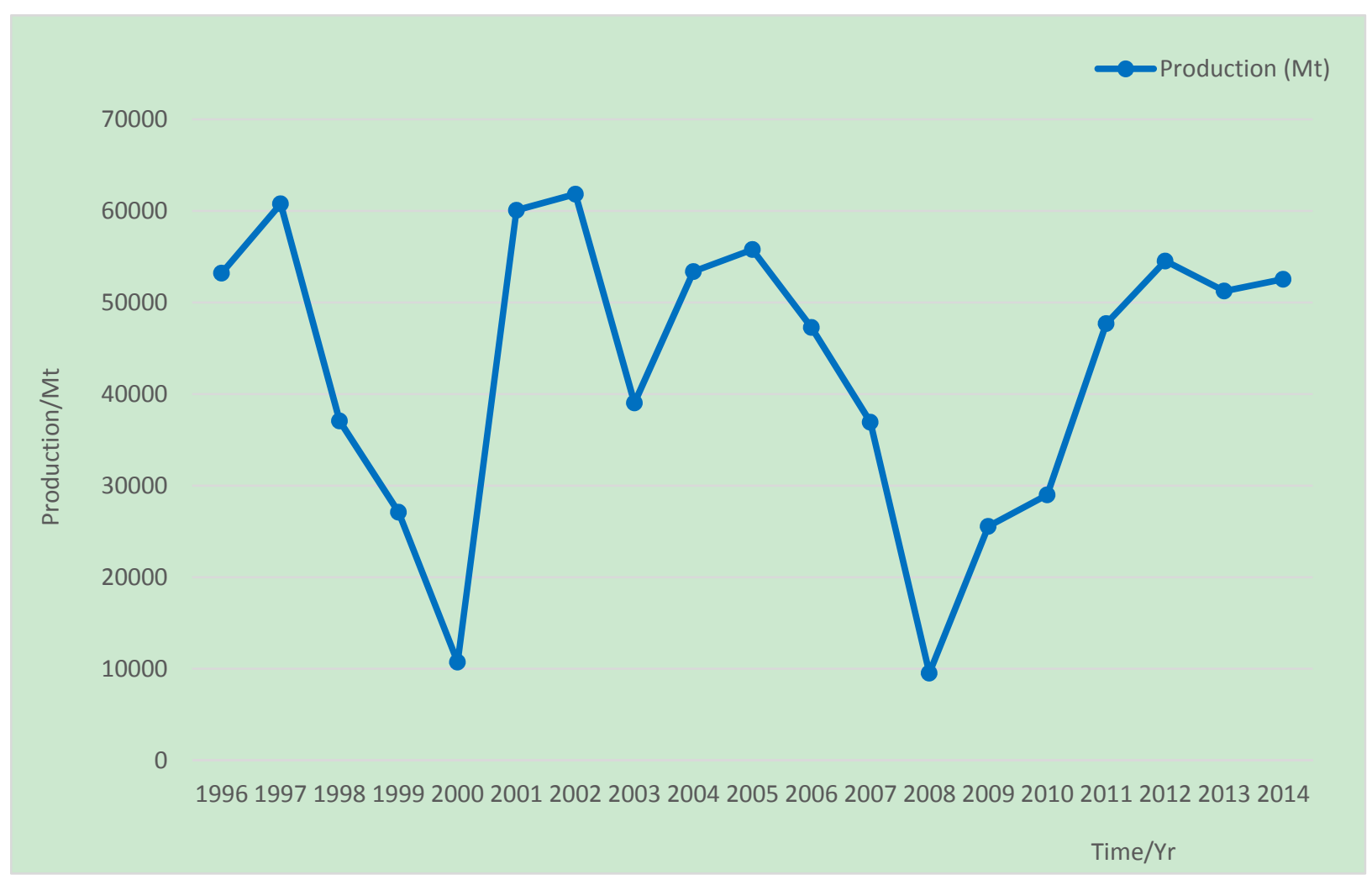

Figure 4. Annual salt production levels at the Songor Salt Project

Source: Songor Salt Project

\subsection{Exploring the Impacts of Temperature and Rainfall on Salt Production}

To ascertain the impacts of temperature and rainfall variability on the levels of salt production, a linear multiple regression model was used. In this model, Salt production (dependent variable) was regressed against temperature and rainfall (independent variables). The results of the model indicate that the increase in temperature decreases with salt production and an increase in rainfall increases with that of salt production. Although the impacts of temperature $(P=\mathbf{0 . 0 7})$ and rainfall $(P=\mathbf{0 . 6 0})$ are not statistically significant, the results reveal that an increase in $1^{\circ} \mathrm{C}$ temperature will lead to a decrease of $\mathbf{- 0 . 4 8 8}$ metric tons of salt production and vice versa. Also, the model predicted that if there is an increase in $1 \mathrm{~mm}$ of rainfall, it will lead to an increase in 0.142 tons of salt production and vice versa (Coefficient of Determination $51.4 \%, R^{2}=0.514 ; P>0.05$ ). These results do not fully reflect the trends of both rainfall and temperature patterns as it is in the study area. The decrease in salt production in Songor lagoon with the increasing temperature trends is consistent. However, the trend of rainfall indicates a contrary situation in the background since rainfall continues to decrease in the study area.

Table 1. Multiple regression model outcome on the impacts of temperature and rainfall on salt production

\begin{tabular}{ccccc}
\hline Salt Production & Standard-error & Regression Coefficient & t-value & P-value \\
\hline Rainfall & 116.3 & 0.142 & 0.57 & 0.577 \\
Temperature & $-28,427.1$ & -0.488 & -1.97 & 0.073 \\
Constant & $827,175.4$ & - & 2.05 & 0.063 \\
\hline
\end{tabular}

$R^{2}=0.514 ;$ Coefficient of Determination $=51.4 \% ; P>0.05 ; C I=95 \%$

\section{Discussion}

\subsection{The Reality of Climate Variability}

The results of the data recorded over the years have shown that temperatures in the area have increased over the 
years whilst rainfall patterns continue to experience an erratic trajectory. This evidence suggests that climate change is happening and its impacts will be severe especially for the vulnerable in society. These findings were found to be consistent with the findings of that of IPCC reports and other studies that climate change is unequivocal (IPCC, 2014; Ahenkan et al., 2012; Adiku et al., 2011, Fatma, 2010). Climate change presents a great challenge for the community dwellers whose livelihoods are dependent on climate change sensitive sectors such as rain-fed agriculture, water, ecosystem services and resources including the salt sector. Adaptation now is not an option but a compelling responsibility that must be embraced to safe and protect the most vulnerable and build their resilience in the face of climate variability.

\subsection{Impacts of Rainfall and Temperature Variability on the Songor Salt Production}

The result has clearly demonstrated that variability in both rainfall and temperature do have a link and an effect on the level of salt production. It was indicated that an increase in $1 \mathrm{~mm}$ of rainfall will cause an increase of $0.142 \mathrm{Mt}$ of salt produced and the reverse is true. For temperature, an increase in $1^{\circ} \mathrm{C}$ will lead to a decrease in 0.488 of salt produced and vice versa. These results suggest that the increasing temperature in the study area presents a big challenge for the salt industry since it continues to experience an upward trend and been projected to even increase in the coming years if measures are not put in place to curb down greenhouse gasses emission. However, contrary to the findings in Bhar et al., (2015), they argued that higher temperature results in higher evaporation leading to more production of salt per unit time from the brine. This means that increasing temperature can equally be an opportunity for the salt sector. Rainfall has been shown to decline, its linear relationship with the salt production as seen in the model will have a rather undesirable effect on the salt industry where a continuous decline as projected, will mean a continuous decline in salt production. Although the impacts of these variables appear not to be statistically significant yet these present important concerns for the salt industry and especially the communities that depend on it for their livelihoods. These findings presents interesting opportunities and the need for more pragmatic measures to exploit these opportunities that increasing temperature presents to the salt industry and minimize the negative impacts of a continuous decline in rainfall pattern for a sustainable salt industry that will continue to better the lives of the communities that depend on these commodities as their sources of income and subsistence.

\section{Conclusion and Recommendations}

The results of the study indicate that the salt industry is sensitive to climate change and that climate change does have an impact on the yield levels of salt produced in a given year. The study demonstrates that variability in both temperature and rainfall patterns at the Songor lagoon account for about $51.4 \%$ reduction in annual salt production levels at the Songor salt project. The study shows that temperature is increasing in the area with a negative impact on the level of salt produced which presents a major threat to the salt industry and for that matter, the livelihoods of communities that rely on these provisioning ecosystem services are at increased risks. The results have shown a decreasing trend of rainfall pattern with a positive impact on the production levels of salt produced although data on rainfall pattern in the study area is on the contrary. There is a mix of influence that climate change will have on the salt industry in the coming years for which proactive measures for minimizing losses and optimizing yields of the salt community must be seriously pursued. Therefore for long-term sustainability of the salt industry, adoption and mainstreaming of climate change adaptation strategy in the salt sector into the overall national adaptation policy is imperative. Investment in infrastructure and storage facilities to produce and store the salt produce to avoid harvest losses and leakages are also essential to buffer the impacts of climate change. Besides the pressing challenges of land acquisition issues, low investment and lack of proper technology in inter-alia that currently bedeviled the salt industry, climate change is noted to exacerbate these problems and will further worsen the production of the salt commodity in the country. This, therefore, calls for comprehensive and integrated efforts from all the relevant stakeholders to play their part in coming together to salvage the salt industry for sustainable economic development. Certainly, the operationalization of the existing policies regarding the salt industry is deemed urgent and paramount than ever to ensure local communities' livelihoods are not forfeited and to achieving the Sustainable Development Goals.

\section{Acknowledgments}

The authors are grateful for the generous support of the Building Capacity to meet the Climate Change Challenge (B4-C) project under the collaboration of the Open Society Foundation which has helped finance this research.

\section{References}

Adiku, G. K. S. (2011). Farm-Oriented Coping Strategies for Minimizing Climate Variability Impact on Agricultural Production in Ghana. Ghana policy journal special edition on climate change, 58-67. 
Amato, D. D., Rekola, M., Wan, M., Cai, D., \& Toppinen, A. (2017). Effects of Industrial Plantations on Ecosystem Service and Livelihoods: Perspectives of Rural Communities in China. Land Use Policy, 63, 266-278. https://doi.org/10.1016/j.landusepol.2017.01.044

Badjeck, M. C., Allison, H. E., Halls, A. S., \& Dulvy, N. K. (2009). Impacts of climate variability and change on fishery Based Livelihoods. Marine Policy.

Bangash, R. F., Passuello, A., Sanchez-Canales, M., Terrado, M., Lopez, A., Elorza, F. J., ... Schuhmacher, M. (2013). Ecosystem Services in Mediterranean River Basin: Climate Change Impact on Water Provisioning and Erosion Control. Sci Total Environ, 458-460, 246-255. https://doi.org/10.1016/j.scitotenv.2013.04.025

Bennett, E. M. et al. (2015). Linking Biodiversity, Ecosystem Services, and Human Well-being: three challenges for designing research for sustainability. Current Opinion in Environmental Sustainability, 14, 76-85. https://doi.org/10.1016/j.cosust.2015.03.007

Berbes-Blazquez, M. (2012). A Participatory Assessment of Ecosystem Services and Human Wellbeing in Rural $\begin{array}{lllll}\text { Costa Rica Using Photo-Voice. Environ } & \text { Manage, }\end{array}$ https://doi.org/10.1007/s00267-012-9822-9

Bhat, A. H., Sharma, K. C., \& Banday, U. J. (2015). The Impact of Climatic Variability on Salt Production in Sambhar Lake, a Ramsar Wetland of Rajasthan, India. Middle-East Journal of Scientific Research, 23(9).

Boon, E., \& Ahenkan, A. (2012). Assessing Climate Change Impacts on Ecosystem Services and Livelihoods in Ghana. Case Studies of the Communities around the Sui Forest Reserve J. Ecography, 3(2).

Fatma, D. (2010). Climate Change Vulnerability, Impacts, and Adaptation. Why Gender Matter, Gender and Development, 10(2), 10-20.

Ghana Salt Strategy. (2009). Salt Strategy for the Salt sector Report. Ghana Export Promotion Council, Ministry of Trade and Industry, Accra- Ghana (unpublished).

IPCC. (2013). Summary for Policymakers in Climate Change 2013: The Physical Science Basis. The contribution of Working Group I to the Fifth Assessment Report of the Intergovernmental Panel on Climate Change. Cambridge University Press, Cambridge, United Kingdom, and New York NY, USA.

Justice, T. M., \& Ebo, B. (2013). Ghana's Salt Industry: A Neglected Sector for Economic Development. Resource Policy, 38, 288-294. https://doi.org/10.1016/j.resourpol.2013.06.002

Millennium Ecosystem Assessment. (MEA, 2005). Ecosystems and Human Well-being: Synthesis. Island Press, Washington, DC.

\section{Copyrights}

Copyright for this article is retained by the author(s), with first publication rights granted to the journal.

This is an open-access article distributed under the terms and conditions of the Creative Commons Attribution license (http://creativecommons.org/licenses/by/4.0/). 